\title{
What about nurses' competencies in Europe?- Translation process of the Nurse Professional Competence Scale into German within the European Network of Nursing Academies and its use
}

\author{
Maria Mischo-Kelling*1, Andrea Thiekötter ${ }^{2}$ \\ ${ }^{1}$ RWU Hochschule Ravensburg-Weingarten, University of Applied Sciences, Germany \\ ${ }^{2}$ Fliedner Fachhochschule Düsseldorf, University of Applied Sciences, Germany
}

Received: September 2, 2021

DOI: $10.5430 /$ jnep.v12n2p92
Accepted: September 25, $2021 \quad$ Online Published: October 22, 2021

URL: https://doi.org/10.5430/jnep.v12n2p92

\begin{abstract}
The link between the level of qualification described as competence of the nursing staff and the patient outcome is repeatedly indicated in patient's safety studies. The Bologna process initiated in 1999 triggered a Europe-wide reform process in the field of education, leading to reforms in nursing education in Europe that promoted the academization of nursing in many countries. In this context, a shift from teaching to learning outcomes occurred which spurred the development of competence frameworks at the European, national and profession-specific level. Competence measurement instruments are important for improving nursing education as well as nursing practice. Studies using such instruments can point to the strength and limitations of the educational and of the health care system of the countries under study. The aim of this article is to describe the translation process of the English version of the Nurse Professional Competence (NPC) Scale to create a German version to be used within German-speaking countries within the European Network of Nursing Academies (ENNA). The background of translating the NPC Scale from English into German is a European research project initiated by ENNA in which 11 European Higher Education Institutes participated. The article proceeds by providing information about nursing work in Austria, Germany and Switzerland. By accounting for the nationally specific conditions of nursing education and by describing the translation process, the study points to the relevance of context specific conditions for measuring self-reported professional competences. Making transparent the translation process supports the applicability of this scale in other research projects.
\end{abstract}

Key Words: Nursing education, Competence in nursing, Instrument, NPC-Scale, Translation of NPC-Scale

\section{INTRODUCTION}

\subsection{The role of nursing education for patient safety}

Studies by Linda Aiken and colleagues in the US and Europe, covering a period of more than 20 years, have repeatedly drawn attention to the link between the qualification level of nurses, the quality of care and patient safety. ${ }^{[1-3]}$ Research in the context of the European Registered Nurse Forecasting (RN4Cast) study confirmed the relationship between the qualification level of nurses and patient mortality that Aiken et al. observed in the US. ${ }^{[4]}$ These studies have shown that higher qualification in nursing correlate with lower risks for patients. ${ }^{[5]}$ Anne M. Rafferty, ${ }^{[6]}$ referring to a paper by Aiken

*Correspondence: Maria Mischo-Kelling; Email: mischokelling@rwu.de; Address: RWU Hochschule Ravensburg-Weingarten, University of Applied Sciences, Germany. 
et al., ${ }^{[2]}$ concluded "if all hospitals in the 12 countries in our study had at least $60 \%$ bachelor's nurses and nurse workloads of no more than six patients each, more than 3,500 deaths a year might be prevented".

This article focuses on the use of a self-reported instrument for measuring professional nurse's competences in three German speaking countries, Austria, Germany, and Switzerland. All three countries participated in a European research project undertaken by the European Network of Nursing Academies (ENNA), which aimed for the comparison of the qualification of nursing graduates as expressed in their competencies using the Nurse Professional Competence Scale (NPC-Scale), previously developed by Swedish colleagues. To understand the context of the study, information is provided regarding the working conditions for nurses in these three countries and the qualification level of nurses. In our discussion of the application of this instrument to Germany, Austria and Switzerland, the Swedish context serves as a reference point. A report on nursing in 14 European countries based on the results of the RN4Cast study underlines that Sweden is more advanced in nursing education in relation to Switzerland and Germany. ${ }^{[7]}$ In the Swedish RN4Cast study $60 \%$ of the 11,000 participating registered nurses had a bachelor degree, ${ }^{[8]}$ while no percentage was reported for the German or Swiss RN4Cast study. ${ }^{[9,10]}$

\subsection{Health care workforce}

Despite efforts in upgrading qualification levels of the nursing healthcare workforce in Europe, all European countries are struggling with the effects of demographic change due to an aging population and the increase in chronic diseases (non-communicable diseases, NCD) and multi-morbidity. In order to meet today's health challenges and to cope with the challenges of reorienting health systems to practice personcentred approaches international organisations such as the World Health Organisation (WHO) ${ }^{[11]}$ and the Organisation for Economic Co-operation and Development (OECD) ${ }^{[12]}$ emphasize the vital role of a highly qualified healthcare workforce. Nurses are the biggest professional group in the healthcare system and as such they play a key role in delivering safe and high-quality care. ${ }^{[13]}$ Even though health and social systems employ more workers than ever before the distribution of nurses varies greatly among OECD countries. ${ }^{[12]}$ In table 1 , the three indicators, nurses to 100,000 inhabitants, nurses to 1 doctor and nurses with a graduate degree to 100,000 inhabitants exemplify this variation for the four selected countries.

Table 1. Distribution of nurses in selected OECD-Countries ${ }^{[12]}$

\begin{tabular}{lllll}
\hline \multirow{2}{*}{ OECD 2019 } & $\begin{array}{l}\text { Population } \\
\text { Eurostat 2019 }\end{array}$ & $\begin{array}{l}\text { OECD 2019 } \\
\text { nurses/100,000 Population }\end{array}$ & $\begin{array}{l}\text { OECD 2019 } \\
\text { nurses/1 doctor }\end{array}$ & $\begin{array}{l}\text { OECDNursing } \\
\text { graduates/100,000 population }\end{array}$ \\
\hline AUT (Austria) & 8.9 million & 6.9 nurses & 2.5 nurses & 34.5 nurse graduates \\
CHE (Switzerland) & 8.5 million & 17.2 nurses & 4.0 nurses & 100.9 nurse graduates \\
GER (Germany) & 83.0 million & 12.9 nurses & 3.0 nurses & 54.5 nurse graduates \\
SWE (Sweden) & 10.0 million & 10.9 nurses & 2.7 nurses & 39.2 nurse graduates \\
\hline
\end{tabular}

Switzerland, a country with a population of only 8.5 million inhabitants, has the best ratio of the four selected countries with 17.2 nurses to 100,000 people. In all three indicators, it clearly stands out from the other three countries considered. Austria with roughly the same population comes off poorly in relation to Switzerland, Sweden and Germany.

The report by Rafferty et al. ${ }^{[7]}$ highlights the varying working conditions in Sweden, Germany and Switzerland. According to Zander-Jentsch et al., ${ }^{[9]}$ nurses of the participating German hospitals in the RN4Cast study reported the worst nurse-patient-ratio 10:1 while in the Swiss RN4Cast study the average ratio was 5:1, ranging from $3: 1$ to $10: 1$ between hospitals. ${ }^{[10]}$ Furthermore, the report emphasizes for Sweden, Switzerland and Germany how developments in nursing are influenced by the history of the nursing profession and that of the respective country. This is particularly evident in

Published by Sciedu Press the area of nursing education. Unfortunately, Austria was not part of the study.

Zander et al. ${ }^{[5]}$ reported existing variations of educational preparation of nurses within European countries despite the educational reforms inspired by the Bologna Process since 1999. In sum, differences in nursing education and in working conditions can be assumed in the four countries under review.

\subsection{European network of nursing academies}

Nursing qualification, the quality of nursing care and patient safety issues are at the core of the work of the European Network of Nursing Academies (ENNA). ENNA was officially founded in 2012. Member academies are from nine European countries: Austria, Germany, Italy, Lithuania, Portugal, Norway, Sweden, Switzerland, and The Netherland. 
Early in 2015, the ENNA partners developed the idea for a European study among the member academies of ENNA to measure self-reported competencies of bachelor students at the end of their bachelor programs using the Nurse Professional Competency Scale (NPC-Scale). A core objective of the study was to engage further with the observed link between qualification level as expressed in competencies and patient safety.

\subsection{ENNA-NPC research project}

The ENNA-NPC-research project took place within 11 higher education institutions (HEIs) in Austria, Germany, Norway, Portugal, Sweden, and Switzerland. As several academies of ENNA belong to German speaking countries, there was great need and interest to translate the English 88-item NPC-Scale into German. An expert group of the German speaking countries was formed for the translation. The translation process was following the same translation process as described by the Swedish NPC-research group for translating the original Swedish NPC-Scale, comprising 88-item, from Swedish to English. ${ }^{[14]}$ This English version of the NPC-Scale was the starting point of the translation process from English into German. The outcome of this translation process was a German version of the NPC-Scale. Only the availability of a German-language NPC-Scale enabled the German speaking countries to participate in the planned European research study. The study aimed at comparing the self-assessed competences among students from HEIs at the end of their bachelor programme using the 88-item NPC-Scale. Participation was voluntary. Data collection took place from October 2015 to June 2017. Altogether, 747 students completed the survey. Of these, 268 students came from South Europe, 160 from central Europe and 318 from Northern Europe. More details of the study are described in the article "Nurse professional competence (NPC) assessed among newly graduated nurses in higher educational institutions in Europe" by Nilsson et al. ${ }^{[15]}$

\subsection{The nurse professional competence scale (NPC) re- search project}

The Nurse Professional Competence Scale (NPC-Scale) was primarily developed by a Swedish research group to measure nursing students and registered nurses' competence. The developers based the 88-item of the Scale on Swedish National guidelines and on the World Health Organization's European Strategy for Nursing and Midwifery. ${ }^{[14]}$ The reliability and validity of the Scale has been demonstrated in studies by Nilsson et al. ${ }^{[16]}$ The 88 -item NPC-Scale covers the following eight competence areas (CA):

1) Nursing care
2) Value-based nursing care

3) Medical and technical care

4) Teaching/Learning and support

5) Documentation and Information Technology

6) Legislation in Nursing and Safety Planning

7) Leadership in and Development of Nursing

8) Education and Supervision of staff and students. ${ }^{[17]}$

In the Appendix the competence areas and the corresponding items are listed.

The Swedish NPC-Research group published the results of studies using the NPC-Scale and reported them at international conferences. The received feedback and international interest in the NPC-Scale motivated the Swedish NPC research group to translate the original Swedish version of the NPC-Scale from Swedish into English, so researchers worldwide can use the instrument. ${ }^{[17]}$

\section{GENERAL BACKGROUND - NURSING ED- uCation in Austria, Germany, Swe- DEN, AND SWITZERLAND}

Before describing the translation process, general background information regarding nursing education in the three German speaking countries represented within ENNA will be given against the background of the Bologna Process initiated in 1999 in the European Union. As mentioned above, Sweden will serve as a reference point. This background information serves to contextualize the translation process as part of the ENNA-NPC-research.

\subsection{Bologna process}

Nursing education in Austria, Germany and Switzerland shares similar problems with respect to moving nursing education into higher education. In contrast to Austria and Switzerland, the educational systems in the former German Democratic Republic (GDR) and West Germany differed from one another including nursing education. After the fall of the Berlin Wall in 1989, the academization process in nursing in the united Germany gained new momentum, which is reflected in the growing nursing programmes primarily at Universities of Applied Sciences in the 1990s. ${ }^{[18]}$

In 1999, the Bologna Declaration was signed by 29 ministers of education, among them ministers of education from Austria, Germany, Sweden, and Switzerland. The declaration was an important step for realising the vision of the ministers of education of a European Higher Education Area (EHEA). The resulting change process within the educational systems of the involved countries was a voluntary process in which national educational systems were transformed into an educational system consisting at first of two main cycles,

ISSN 1925-4040 E-ISSN 1925-4059 
undergraduate and graduate study. As a result, the academic system is now based on three cycles of academic qualification: bachelors, masters and doctoral degrees. ${ }^{[15]}$

This educational movement affected nursing education in the European countries in various ways. ${ }^{[19]}$ However, more than 20 years before Bologna, the process of harmonization and mutual recognition of nursing education had started which had resulted in the EU directives 77/452/ECC and 77/453 from June 27th, 1977. The two directives regulated the mutual recognition of certificates as well as minimum entrance requirements for nursing education, its duration and amount of minimum hours for theoretical and clinical-practical training. ${ }^{[19]}$ The Bologna process opened new possibilities for nursing education within the EU, which was taken up differently within the member states and Switzerland that aligned to the EU regulation.

In the Scandinavian countries, the shift from vocational training to higher education had already taken place long before the Bologna Process. ${ }^{[20,21]}$ For example, in Sweden this movement started in 1982 and resulted in a two-year academic education, lengthened to a three-year academic education in 1993. Since 2007, as one result of the Bologna Process, "all registered nurse education in Sweden leads to a bachelor of science degree in nursing". ${ }^{[8]}$ In contrast, nursing education in Austria, Switzerland and Germany remained largely within the traditional vocational education system (VES). In these countries the academization process of the nursing profession occurred very slowly and differently, despite the efforts beginning in the 1970s.

In 2004, the enactment of the Vocational Training Act in Switzerland facilitated the transfer of nursing education to general vocational training. ${ }^{[22]}$ As a result, nursing education is now embedded within upper secondary and tertiary levels of education. Another developmental step was reached with the Vocational and Professional Education and Training Act. As Schwendimann et al. ${ }^{[10]}$ noted:

“(...) for the first time in Swiss nursing education a unified compulsory curriculum framework was implemented in 2009 to which all professional education and training colleges have to align their nursing education and training programmes (Oda Sante 2007). The curriculum follows Directive 2005/36/EC of the European Parliament and of the Council on the recognition of professional qualifications (Eur-LEX 2015)".

The Swiss educational system is characterized by the principle "no graduation without connection" ${ }^{[22]}$ which allows nursing to develop its educational systems according to the requirements of the Bologna Process as well as to catch up with European and international developments.

In Austria too, different educational paths in nursing exist. The academization process goes back into the 1970s, but it took more than two decades until in 1998 a nursing programme was offered by the University of Wien leading to a diploma in nursing science. A few years later, that is, in the winter term $2004 / 5$, two other study programmes in nursing started at the Medical University of Graz and at the UMIT Tyrol, Hall in Tirol, followed by another nursing programme at the Paracelsus Private Medical University Salzburg in the winter term 2007/8. ${ }^{[23]}$ In 2016, a new law amendment introduced a reform of nursing education encompassing five educational levels from nurse education for nurse assistance to special nurse assistance at the vocational training level to nursing education in higher education (HE) at the bachelor, master and doctoral level. The transition period for general nursing from the vocational training system to HE should be completed by $2024 .{ }^{[23]}$

As mentioned before, the academization process in Germany had precursors in the old as well as in the new federal states: From the 1990s it saw a proliferation of nursing programmes at Universities of Applied Sciences for nurse teachers ${ }^{[24]}$ and nurse managers. ${ }^{[25]}$ Both the German Nursing Law, enacted in 2004, and the Geriatric Nursing Law, enacted in 2003, had a model clause which opened up the possibility of establishing model study programmes for general nursing at the bachelor level, a possibility widely used after the two nursing acts came into force. ${ }^{[26]}$ The development process initiated in general nursing education was further advanced by the recommendation of the German Council of Science and Humanities ${ }^{[27]}$ to provide academic training for 10 to 20 percent of each new cohort of nursing students. Again, it was mainly at Universities of Applied Sciences that nursing study programmes were created, which differed from one another in terms of curriculum design, module content, duration and credits to achieve, ranging from 180 to 240 ECTS. ${ }^{[9,15]}$ Reuschenbach \& Darmann-Finck ${ }^{[26]}$ assign these various study programmes to three structural models (A, B and C). Only in model A the HEI is responsible for the entire educational programme which is the rule rather than the exception about nursing education in the European context.

With the new Nurse Professions Reform Act, enacted in January $2020,{ }^{[28]}$ the three nursing branches general nursing, pediatric nursing and geriatric nursing are now regulated in one act. Furthermore, this law provides nursing education in higher education in addition to the traditional vocational educational path in nursing education. For the first time, frameworks for curricula for theoretical and practical 
learning based on competencies have been developed which will contribute to the convergence of nursing education on the whole, whether in traditional vocational education or in higher education. ${ }^{[29]}$

\subsection{Qualification frameworks and competencies in the four countries}

Irrespective of the developments within nursing education in the four countries, the shift from teaching to learning outcomes as an important part of the Bologna Process spurred the development of competency frameworks. The European Qualification Framework (EQF) for lifelong learning served as a reference point for the development of national qualification frameworks such as the German Qualification Framework (DQF), which were further translated into a qualification framework for German universities. An important characteristic of these frameworks is their differentiation of competences at different educational levels. Within these frameworks the vocational nursing training resides at level 4 while the bachelor's degree is located at level 6. Within the existing competence frameworks competences are treated and understood differently. This posed a challenge in developing a profession specific qualification framework for nursing in HE in Germany. ${ }^{[30]}$

Also, in Austria and in Switzerland competence models have been developed. Beside the EQF and the respective national qualification framework, the Austria Health and Nursing Association for example oriented itself to different models such as the 'ICN Nursing Care Continuum Framework and Competencies" and the "International Classification of Nursing Practice (ICNP)". [31]

In summary, the German speaking countries participating in the ENNA NPC project not only have a high variance in the study programmes, but also relate to different competence frameworks. In the planned ENNA NPC research project the nursing students of the participating HEIs should all assess their competences using the same Scale, thus the NPC-Scale had to be translated into the respective language of the participating universities, e,g. into German.

\subsection{Aim of the study}

The aim of this article is to describe the translation process of the English version of the Nurse Professional Competence (NPC) Scale to create a German version to be used within German-speaking countries within the European Network of Nursing Academies (ENNA).

96

\section{THE TRANSLATION PROCESS OF THE EN- GLISH VERSION OF THE NPC-SCALE INTO GERMAN}

The translation and adaption process followed the structure recommended by the Swedish NPC-research group. These colleagues followed the guidelines of the translation procedure by the $\mathrm{WHO}^{[32]}$ and, in addition, modified the procedural steps ancillary ${ }^{[11]}$ Therefore, and as the intended guideline for further use of the English version of the NPCScale, the following translation procedure from the English into the German language was hereby equally oriented to the WHO's standard, which contains originally four steps: 1) Forward translation, 2) Expert panel back translation, 3) Pretesting and cognitive interviewing and 4) Final version. The WHO guidelines including the four steps were extended to eight steps for the translation of the NPC-Scale that Nilsson et al. ${ }^{[14]}$ developed: 1) Forward translation, 2) Expert panel review and revision of the first version, 3) Back translation, 4) Expert panel review and revision, 5) Review of suggested version by professional language editor, 6) Expert panelassessment of language editing, 7) Pretesting and cognitive interviews, and finally 8) Expert panel review of the pre-tested version.

Along these steps, the translation of the NPC-Scale from English to German was pursued in line with what Nilsson et al., ${ }^{[14]}$ the original developers, have recommended in their article "Process of translation and adaptation of instruments" for using the Scale in different countries worldwide.

\subsection{Forward translation from English into German by a professional translator - step 1}

First, a team of scientific and bilingual professionals was created which attended the whole translation process. This includes beside the authors three other members of ENNA. They all have expertise in developing, translating, and testing scientific instruments in the field of nursing science and nursing education. In addition, two external professional translators were involved in the translation process.

For step 1, the first external professional translator translated the NPC-Scale from the English into the German language which resulted in the first version and was ready by October 14th, 2015.

\subsection{2 Expert panel review and revision of the first Ger- man language version - step 2}

After the first German language version was developed, the professional team reviewed this version during several online meetings. In this phase, the group was eager to find nursing specific terms, which are commonly used in the German professional nursing literature. Therefore, nursing books pub- 
lished by the publishing house Hogrefe, the nursing books of which are used in all three German speaking countries (Austria, Germany, and Switzerland), served as reference points. Unclear terms of the English version such as in item 4 "nursing prescription" were discussed dependent on the tasks of nurses in Sweden compared to those in the German speaking countries because in the latter nursing prescription does not exist as an independent task of nurses. Other words like in item 28 "treatment" or in item 52 "provide contact details" were checked in the original Swedish NPC-Scale by a member of the professional team whose mother tongue is Swedish and who is fluent in German too. These words were discussed, modified, and ended in the second German language version.

\subsection{Back translation from the German into the English language version - step 3}

For realizing step 3, the second external professional translator did the back translation of the second German version into the English language. This professional translator, whose mother tongues are English and German, works at a department of nursing science at a German University.

\subsection{Expert panel review and revision of the German ver- sion - step 4}

Afterwards, the professional team compared the back translated English version of the NPC-Scale with the first German version. Still, a few words like in item 72 "co-workers/staff" which meant "colleagues" were discussed whilst comparing, checking, discussing, and consenting in several online meetings.

\subsection{Review of suggested German version by professional English language translator - step 5}

As the result of step 4, the modified and reconfirmed translated German version of the NPC-Scale was edited by the second professional translator for the last time again. Hereby, only some minor changes were made.

\subsection{Expert panelassessment of language editing - step 6} Again, the professional team looked at the German version of the NPC-Scale and considered the last few suggestions of the second professional translator who edited it. The changes related only to language specific terms and did not focus on specific nursing contents of the Scale.

\subsection{Pretesting the Scale - step 7}

Before using the last German version of the NPC-Scale within the ENNA NPC-research project, pre-testing of the Scale was necessary. One target group for the pre-test were 21 students who finished the bachelor programme in nursing after the winter term 2015/16. Participation at the pilot testing was voluntary. On January 27th 2016, 18 students were available for answering the questionnaire. Of these, one student did not receive the questionnaire since she had to repeat the final year. Another student could not participate out of other reasons. The remaining 16 students filled out the questionnaire consisting of three parts:

1) part A - socio-demographic questions,

2) part B - the 88-item NPC-Scale and,

3) part $\mathrm{C}-$ concluding questions.

Furthermore, we asked the students to give written feedback on a provided extra feedback-sheet. 14 of the 16 students answered our feedback questions and confirmed that all 88 items of the NPC-Scale were understandable and comprehensible. One student remarked that questions in Part $\mathrm{C}$ should differentiate more clearly between the traditional vocational training and the bachelor programme. Another student gave a suggestion for the final question of Part $\mathrm{C}$. The second group who carried out the communicative validation of the survey consisted of one master student and one $\mathrm{PhD}$-student in nursing science at other universities in Germany.

\subsection{Expert panel review of pretested version - step 8}

The feedback of the two pretesting groups were again discussed within the professional team. Thereof, last changes regarding the final part - Part $\mathrm{C}$ - of the survey were made. This marked the last step of the translation process. The final version of the German NPC 88 item Scale was ready to be used within the European NPC-research project on June 20th, 2016. Prior to that, it was presented at an official ENNAmeeting in May 2016, at which the representatives of the other two German-speaking countries, Austria and Switzerland, agreed to use this Scale in the ENNA-NPC-research project.

\section{RESUlt of THE TRANSLATION PROCESS}

\subsection{German Version of the NPC-Scale}

This article described the iterative translation process used to produce a German NPC-Scale consisting of 88-item to use within the ENNA-NPC-research project. The basis of the translation process was the English version of the 88-item NPC-Scale. The members of the German professional expert group got support during the translation process by two Swedish colleagues. Both are members of the Swedish NPCresearch group. In sum, the German-Swedish composition of the expert panel group allowed culture specific clarifications of specific terms and their meanings in the Swedish nursing context. This background knowledge was helpful in as such as it allowed the transfer of the meanings from one language and professional context to another language and professional context. In addition, the German professional 
expert group was very careful during the translation process to find linguistic formulations that would be understood in the same way in all three German-speaking countries despite linguistic differences and national specific development processes in nursing education.

\subsection{Use of the NPC-Scale within ENNA and beyond}

As mentioned above, the Swedish NPC-Scale has rendered great interest from researchers internationally, which is why the NPC-research group decided to translate the Scale into English to facilitate international use of the instrument. In addition to the German translation of the NPC-Scale, the Scale has been translated into Norwegian. ${ }^{[33]}$ After using the German NPC-Scale within the ENNA-NPC-research project in the three German speaking countries Austria, Germany, and Switzerland two changes occurred regarding the Scale.

The first change refers to the above-mentioned linguistic challenge. Even if the language is the same, language idioms and meanings of a few words were different and ended into an NPC-Scale German DEU language version. The other German language Scale is the NPC-Scale German AUT language version, which is used in Austria. The AUT Scale was developed after the implementation of the ENNA NPC research project. It is the result of a qualification project (master's thesis) carried out in one HEI belonging to ENNA. For the master thesis the Scale has been subjected to a different translation procedure, ${ }^{[34,35]}$ the "ISPOR Principles of Good Practice: The Cross-Cultural Adaptation Process for Patient Reported Outcome measures". ${ }^{[34]}$ Switzerland has not developed a specific German language version, yet.

The second change is related to the work of the Swedish NPCresearch group, who reduced the 88 -item Scale to 35 -item. ${ }^{[36]}$ In this work the Swedish NPC-research group changed the five-point Likert Scale to a seven-point Likert Scale. In both German language versions, the Scales have been adapted according to the work of the Swedish NPC-research group. Researchers from German speaking countries are free to choose among the NPC 88-item and/or the NPC 35-item in the German DEU language version and the German AUT language version. Meanwhile two HEI's in Germany have asked ENNA to be allowed to use the German DEU language version.

\section{Discussion}

The original Swedish NPC-Scale refers to international (like WHO) and to Swedish national guidelines. As it has been described in the article using such a scale in the context of the three German speaking countries can prove challenging due to the fact that nursing education in higher education differs in Germany and between the German speaking countries.
As observed in the ENNA NPC-research project the educational background and experience in nursing practice influence how students at the same educational level, the bachelor level, will assess their competences. While nursing programmes across Sweden at the bachelor level are constructed in the same manner, in Germany, for example, the nursing programmes at the bachelor level pose another challenge due to the variability, duration and curriculum design. Looking at the German-speaking countries, the results of the ENNANPC study indicate that the German-speaking students rated their own competencies significantly higher than their colleagues from southern and northern Europe on six out of eight competence areas (CA 1,2,3,4, 6 and 7, see table 2 for the $\mathrm{CAs}) \cdot{ }^{[15]}$ As mentioned above, nursing programmes in the German-speaking countries differ from the ones in the participating countries in South and North Europe. For example, depending on the entry point of the study programme the student population can have gained more in-depth work experience due to the fact that they already have worked as registered nurses before starting their studies or that they have worked as registered nurses during their last study phase.

Even though the Nursing Professions Reform Act will facilitate the convergence of nursing education in Germany on the vocational as well as at the higher education level, further development processes are needed to ensure that Germany does not lose its international connection. Of the three German-speaking countries, Germany in particular is finding it difficult to fully integrate nursing education into the higher education sector. As the example of these three countries indicate, the assessment results of the NPC-Scale have highlighted the importance of considering nationally specific conditions of nursing education and clinical experiences of students not only for interpretation of the study results, but also to become aware of possible strengths and weaknesses of the countries studied. Comparative studies as the ENNA NPC-research study, or the cited studies by Aiken and colleagues as well as the RN4Cast study are necessary to show historical developments and to point out developmental needs for the nursing profession compared to other countries.

Using instruments like the NPC-Scale in various European countries for measuring competence in nursing are needed to improve nursing education as well as nursing practice in as much as such studies can point to the strength and limitations of the educational system and of the health care environment of the countries under study.

As this article shows all three German speaking countries have made a smaller or bigger progress in nursing education. Nevertheless, all three countries are called upon to heed the call of the $\mathrm{WHO}^{[13]}$ made in its report "State of World's 
nursing", i.e., to invest in nursing education and nursing care so that future generations of nursing professionals will be able to cope with the demands of a future-oriented and person-centred nursing and healthcare system.

The experience of the ENNA-NPC research project and the results point to the need for comparative studies. As the ENNA-NPC project shows, comparing nurses' competences is a major challenge due to the historical development of nursing education in the European countries studied. As the latest Bologna Implementation Report ${ }^{[37]}$ demonstrates, harmonisation of educational pathways is a lengthy undertaking. The harmonisation of nursing education within the European Higher Education Area (EHEA) is an important step towards the OECD's goal of global harmonisation of health professions education to meet the challenges of the Sustainable Development Goals (SDGs) in health. ${ }^{[13]}$ Such harmonisation processes are complicated worldwide by the legally differently regulated roles of nurses. ${ }^{[38]}$ In order to achieve them, however, there is a need for global investment in nursing education and related research. ${ }^{[13]}$ In this con- text, research on nursing competencies as a specific area of research has a central role to play.

The website of the Swedish NPC-research group documents the use of the scale and is already translated in different languages around the world. ${ }^{[39]}$ It contributes to research on nurses' competencies and thus to improve the quality of nursing care and health care for people in need of care. The translation of the NPC scale as a tool for measuring nurses' competencies represents a necessary step forward in nursing research.

\section{ACKNOWLEDGEMENTS}

The authors want to thank the participants of the expert team, whose work is reported here. Especially, the authors want to thank Professor Margret Lepp for her constructive feedback und valuable comments during the process of writing this article.

\section{CONFLICTS OF INTEREST DISClosure}

The authors declare that there is no conflict of interest.

\section{REFERENCES}

[1] Aiken LH, Clarke SP, Cheung RB, et al. Educational levels of hospital nurses and surgical patient mortality. JAMA: The Journal of the American Medical Association. 2003; 290(12): 1617-1623. PMid:14506121 https://doi.org/10.1001/jama.290.12.16 17

[2] Aiken LH, Sloane DM, Bruyneel L, et al. Nurse staffing and education and hospital mortality in nine European countries: A retrospective observational study. Lancet. 2014; 383(9931): 1824-1830. https://doi.org/10.1016/S0140-6736(13)62631-8

[3] Aiken LH, Sloane D, Griffiths P, et al. Nursing skill mix in European hospitals: Cross-sectional study of the association with mortality, patient ratings, and quality of care. BMJ Quality \& Safety. 2016; 26(7): 559-568. PMid:28626086 https : //doi .org/10.1136/bm jqs-2016-005567

[4] Ball JE, Bruyneel L, Aiken LH, et al. Post-operative mortality, missed care and nurse staffing in nine countries: A cross-sectional study. International Journal of Nursing Studies. 2018; 78: 10-15. PMid:28844649 https://doi.org/10.1016/j.ijnurstu. 201 7.08 .004

[5] Zander B, Aiken LH, Busse R. The state of nursing in the European Union. Euro-Health. 2016; 22(1): 3-6. https: //apps.who.int/iris/bitstream/handle/10665/332724/ Eurohealth-22-1-3-6-eng.pdf? sequence=1\&isAllowed=y

[6] Rafferty AM . Nurses as change agents for a better future in health care: The politics of drift and dilution. Health Economics, Policy, and Law. 2018; 13(3-4): 475-491. PMid:29441837 https: //doi.org/10.1017/S1744133117000482

[7] Rafferty AM, Busse R, Zander-Jentsch B, et al. Health policy series: no. 52. Strengthening health systems through nursing: Evidence from 14 European countries. European Observatory on Health
Systems and Policies; WHO Regional Office for Europe. 2019 https://apps.who.int/iris/handle/10665/326183

[8] Alenius LS, Lindqvist R, Tishelman C. Sweden. In A. M. Rafferty, R. Busse, B. Zander-Jentsch, W. Sermeus, \& L. Bruyneel (Eds.), Health policy series: no. 52. Strengthening health systems through nursing: Evidence from 14 European countries (pp. 143-151). European Observatory on Health Systems and Policies; WHO Regional Office for Europe. 2019. Available from: https://www. euro.who.int/en/publications/abstracts /strengthening-health-systems-through-nursing-evi dence-from-14-european-countries-2019

[9] Zander-Jentsch B, Wagner F, Rzayeva N, et al. Germany. In A. M. Rafferty, R. Busse, B. Zander-Jentsch, W. Sermeus, \& L. Bruyneel (Eds.), Health policy series: no. 52. Strengthening health systems through nursing: Evidence from 14 European countries (pp. 43-52). European Observatory on Health Systems and Policies; WHO Regional Office for Europe. 2019. Available from: https://www . euro. who.int/en/publications/abstracts /strengthening-health-systems-through-nursing-evi dence-from-14-european-countries-2019

[10] Schwendimann R, Ausserhofer D, Schubert M, et al. Switzerland In A. M. Rafferty, R. Busse, B. Zander-Jentsch, W. Sermeus, \& L. Bruyneel (Eds.), Health policy series: no. 52. Strengthening health systems through nursing: Evidence from 14 European countries. European Observatory on Health Systems and Policies; WHO Regional Office for Europe. 2019.

[11] World Health Organization. Nursing and midwifery: fact sheet 2020a. Available from: https://www.who.int/news-room/fa ct-sheets/detail/nursing-and-midwifery

[12] OECD. Health at a Glance 2019. 2019. Available from: https://www.oecd-ilibrary.org/content/publication/ 4dd50c09-enhttps://doi.org/10.1787/4dd50c09-en 
[13] World Health Organization. State of the world's nursing report 2020: investing in education, jobs and leadership. 2020b. Available from: https://www.who.int/publications/i/item/978924 0003279

[14] Nilsson J, Gardulf A, Lepp M. Process of translation and adaptation of the nurse professional competence (npc) scale. Journal of Nursing Education and Practice. 2016; 6(1): 100-103. https: //doi.org/10.5430/jnep.v6n1p100

[15] Nilsson J, Mischo-Kelling M, Thiekoetter A, et al. Nurse professional competence (NPC) assessed among newly graduated nurses in higher educational institutions in Europe. Nordic Journal of Nursing Research. 2019; 39(3): 159-167. https://doi .org/10.1177/20 57158519845321

[16] Nilsson J, Johansson E, Egmar AC, et al. Development and validation of a new tool measuring nurses self-reported professional competence-the nurse professional competence (NPC) Scale. Nurse Education Today. 2014; 34(4): 574-580. PMid:23938092 https: //doi.org/10.1016/j.nedt.2013.07.016

[17] Gardulf A, Nilsson J, Florin J, et al. The Nurse Professional Competence (NPC) Scale: Self-reported competence among nursing students on the point of graduation. Nurse Education Today. 2016; 36: 165-171. PMid:26586256 https://doi .org/10.1016/j.ne dt.2015.09.013

[18] Clift JM. Nursing education in Austria, Germany, and Switzerland. Image, Journal of Nursing Scholarship. 1997; 29(1): 8993. PMid:9127547 https://doi.org/10.1111/j.1547-5069. 1997.tb01146.x

[19] Koff SZ. Nursing in the European Union: Anatomy of a Profession, Volume 1. Transaction Publishers. 2016. Available from: http: //gbv. eblib. com/patron/FullRecord. aspx?p=4572812

[20] Hafsteinsdóttir TB, Jónsdóttir H, Kirkevold M, et al. LEADERSHIP IN NURSING: Experiences from the european nordic. SPRINGER NATURE. 2019. PMCid:PMC6917956 https ://doi .org/10.1 007/978-3-030-10964-6

[21] Råholm MB, Hedegaard BL, Löfmark A, et al. Nursing education in Denmark, Finland, Norway and Sweden - from Bachelor's Degree to PhD. Journal of Advanced Nursing. 2010; 66(9): 2126-2137. PMid:20626496 https: //doi.org/10.1111/j.1365-2648.20 $10.05331 . x$

[22] Steudter E. Pflege und Hochschulbildung in der Schweiz. In K.-H. Sahmel (Ed.), Hochschuldidaktik der Pflege und Gesundheitsfachberufe (pp. 121-129). Springer. 2018. https ://doi .org/10.100 7/978-3-662-54875-2_11

[23] Them C, Wetzlmair J, Schulc E. Die Bildungspyramide der Pflegeberufe in Österreich.: Von der Pflegeassistenz bis zum Doktorat der Pflegewissenschaft. In K.-H. Sahmel (Ed.), Hochschuldidaktik der Pflege und Gesundheitsfachberufe (pp. 131-140). Springer. 2018. https://doi.org/10.1007/978-3-662-54875-2_12

[24] Sahmel KH. Die Entwicklung der Pflegelehrer-Bildung in Deutschland - Rückblick und Ausblick. In K.-H. Sahmel (Ed.), Hochschuldidaktik der Pflege und Gesundheitsfachberufe (pp. 41-51). Springer. 2018. https://doi.org/10.1007/978-3-662-54875-2_4

[25] Burkhardt W. Das Studium des Pflege- und Gesundheitsmanagements an Hochschulen: Studiengänge zwischen Betriebswirtschaftslehre, Wirtschaftswissenschaften, Gesundheit und Pflege. In K.-H. Sahmel (Ed.), Hochschuldidaktik der Pflege und Gesundheitsfachberufe (pp.
53-61). Springer. 2018. https : //doi .org/10 .1007/978-3-662 $-54875-2 \_5$

[26] Reuschenbach B, Darmann-Finck I. Pflege studieren - Intentionen, Strukturen und Erfahrungen. In K.-H. Sahmel (Ed.), Hochschuldidaktik der Pflege und Gesundheitsfachberufe (pp. 63-75). Springer. 2018. https://doi .org/10.1007/978-3-662-54875-2_6

[27] Wissenschaftsrat. Empfehlungen zu hochschulischen Qualifikationen für das Gesundheitswesen. Berlin. 2012.

[28] Weiss T, Meißner T, Kempa S. Pflegeberufereformgesetz: Praxiskommentar. Edition Springer Pflege. Springer Gabler. 2018.

[29] Bundesinstitut für Berufsbildung. Rahmenpläne der Fachkommission nach § 53 PflBG: Rahmenlehrpläne für den theoretischen und praktischen Unterricht/Rahmenausbildungspläne für die praktische Ausbildung (2., überarbeitete Auflage 2020). Bundesinstitut für Berufsbildung. 2020.

[30] Hülsken-Giesler M, Korporal J. (Eds.). Fachqualifikationsrahmen Pflege für die hochschulische Bildung: (FQR Pflege 6-8). Purschke+Hensel. 2013.

[31] Österreichischer Gesundheitsund Krankenpflegeverband (OEGKV), Landesverband Steiermark. Kompetenzmodell für Pflegeberufe in Österreich. 2011. Available from: https ://www . oegkv.at/fileadmin/user_upload/Diverse s/OEGKV_Handbuch_Abgabeversion.pdf

[32] World Health Organization (without year). Management of substance abuse: process of translation and adaptation of instrument. Geneva. Available from: https://www.who/int/substance_abuse/re search_tools/translation/en/ (accessed, 30.11.2020)

[33] Skaug EA, Ekman S, Kirchhoff JW. Oversetting, tilpasning og testing av the nurse profes-sional competence scale. Nordisk Sygeplejeforskning. 2020; 10(03): 164-175. https://doi.org/10.18261 /issn.1892-2686-2020-03-03

[34] Kellerer JD, Raab I, Müller G, et al. Übersetzung und kulturelle Adaption der Nurse Professional Competence (NPC) Scale: die deutschsprachige NPC Skala: Ein Selbsteinschätzungsinstrument für Pflegekompetenz. Pflegewissenschaft 1/2-2019. 2019; 21.(1/2): 61-70.

[35] Kellerer JD, Rohringer M, Raab I, et al. Translation and cultural adaptation of the Nurse Professional Competence Scale: The NPC Scale-German AUT language version. Journal of Nursing Education and Practice. 2021; 11(1): 51-58. https ://doi .org/10.5430/jn ep.v11n1p51

[36] Nilsson J, Engström M, Florin J, et al. A short version of the nurse professional competence scale for measuring nurses' self-reported competence. Nurse Education Today. 2018; 71: 233-239. PMid:30321851 https://doi.org/10.1016/j.nedt.2018.09.028

[37] European Commission/EACEA/Eurydice, 2020. The European Higher Education Area in 2020: Bologna Process Implementation Report. Luxembourg: Publications Office of the European Union. Available from: https://eacea.ec.europa.eu/national-polic ies/eurydice/content/european-higher-education-are a-2020-bologna-process-implementation-report_en

[38] Maeda A, Socha-Dietrich K. Skills for the future health workforce: Preparing health profes-sionals for people-centred care. OECD Health Working Papers No. 124. 2021. https ://doi .org/10.178 7/68fb5f08-en

[39] NPC Research Group. Available from: https://www.npcresearc hgroup.com/publications.html, 2021-10-09 